\title{
Detecting and Preventing Internet-Plagiarism in a Foreign Language E-learning Course
}

\author{
doi:10.3991/ijac.v2i2.619 \\ S. Orthaber \\ University of Maribor/Faculty of Logistics, Celje, Slovenia
}

\begin{abstract}
E-learning is becoming an increasingly common if not an essential strategy in academic institutions and the Faculty of Logistics of the University of Maribor, Slovenia is no exception. However, this new teaching mode also brings about new forms of academic misconduct, which is the main topic of this paper. The first proposed methodological approach was to take into account students' general experience, motivation and satisfaction with e-learning from a previously undertaken survey. Then students' submitted assignments from the 8-week foreign language course English in Logistics were analyzed with the objective of finding whether the perception of intellectual property rights of those students who had been warned has changed and what the reasons for plagiarism might have been: did plagiarism attempts somewhat diminish, or did students deliberately continue to copy from the internet? What reasons for plagiarizing other than stress resulting from potential problems of integrating contemporary technology into the learning process may there be?
\end{abstract}

Index Terms-internet plagiarism, e-learning, plagiarism detection software

\section{INTRODUCTION}

New technologies are emerging rapidly in all aspects of our lives and as companies and businesses are trying their best to embrace them, create new competitive advantages and design new trends others might follow, many individuals too, want to follow suit. The same is expected of most higher education institutions, where state-of-theart technologies have been integrated into the entire process to a degree that they have even started transforming traditional modes of teaching. Moreover, as the increasing number of higher education institutions becomes confronted with decreased state funding for students and teaching staff, e-learning seems to be just the right solution to financial issues and at the same time a way for everyone to enhance their much needed computer skills.

\section{IMPLEMENTATION E-LEARNING AT THE FACULTY OF LOGISTICS}

Since Slovenia's declaration of independence in 1991 and its accession to the European Union in 2004, the country has been through an intense transition period that has led to many changes, including changes in Slovenia's higher education system. Within the past three years, the Higher Education Council of the Republic of Slovenia has accredited 24 higher education institutions, of which 18 are private. Many government members are concerned that due to limited financial and human resources the desired level of quality will not be reached. Moreover, due to lack of evaluation processes the success and results of the newly set-up faculties and universities cannot be determined [1]. As a result many schools, faculties and universities are concerned with competitiveness and are trying to win over as many students as possible. At the same time they are striving to replace the decreased state funding by engaging themselves into various research projects, by collaborating with relevant economic sectors and by marketing their education programs to the wider public.

To that end, e-learning is becoming an increasingly common if not essential strategy in academic institutions and the Faculty of Logistics is no exception. The fact that the Faculty, situated in Slovenia's fourth largest town, has a dislocated unit in another smaller town is also one of the reasons why the integration of e-learning at the Faculty already started in its second year of existence in 2006, primarily to save time for both lecturers and students and to cut costs, as all courses were carried out at both locations. Just as logistics deals with the planning and controlling of the flow of materials and information and aims to provide optimum efficiency solutions to all possible processes, the Faculty of Logistics too, wants to do it justice by achieving high quality and reduce costs. That is why the implementation of e-learning was pursued with even greater vigor and intensity as the Faculty opened an additional dislocated unit in another region of the country. Although lectures were still held in auditoriums to a certain extent, students would always upload their assignments and homework to a specially designed online Moodle portal. In the winter semester $2007 / 2008$, e-learning materials have been produced by the lecturers for each module taught and the use of elearning has further expanded. The number of hours of class contact time was cut by half.

\section{A. Components of e-learning in foreign language course}

Traditionally held lectures have been consolidated from 15 to 8-week intense courses. At the moment, the vast majority of courses that are being carried simultaneously at two different locations, are using video-conferencing. Apart from that all of them are using the Moodle portal as part of students' independent study. This calls for increased students' as well as lecturers' workload and input. Foreign-language modules do not use videoconferences out of fear that not only the "personal feel" could be lost but also the rate of potential misunderstandings may arise. Instead, the modules are being carried out as interactively as possible in form of discussions and presentations. Moreover, emphasis was 
given on group work, during which students conduct researches, produce and then submit reports on specific topics which they subsequently present in class.

Assignments are placed on Moodle on a weekly basis, more or less in form of gap fill exercises, quizzes and multiple choice assignments, as well as occasional podcasts and forum discussions. Apart from that additional interactive e-learning materials have now been produced that offer even more possibilities for students to enhance their foreign language skills, which would not be possible to do solely by using Moodle due to its limited capabilities.

\section{Plagiarism at the Faculty of Logistics}

Having already gained some experience with e-learning during the undergraduate and graduate studies abroad, spotting the differences in educational processes was easy but what particularly caught my eye when I started teaching English for specific purposes at the Faculty was the fact that students were unfamiliar with the Intellectual Property Law and the Statute of the University, as they submitted copied materials from online newspapers and encyclopaedias, such as Wikipedia and various other data bases and took them as their own. Furthermore, they were not familiarized with citation methods and were certain that copying material from online sources was not regarded as plagiarism. Sometimes, their assignments on particular themes would even contain absurd data, as students were unable to think critically and question the reliability of online sources.

Much has been written on plagiarism in tertiary education, which in the past decade has become very common with the advancement of the internet. However, in the Statute of the University of Maribor there is no clear-cut definition of plagiarism as such, despite the fact that it qualifies it as a breach of Article 223 of the University Statute thus classifying plagiarism in an essay, a thesis, program or any other written work as a severe offence provided the acquired mark forms part of the overall mark of the module [2]. Should it occur and in case it is reported, the following measures can be used: a student may be issued a warning, a student may face expulsion for either a period of two years or terminal expulsion from the University, or other measures may be taken. Moreover, plagiarism is not only deemed an offence as stated in the Statute of the University of Maribor, it is also contrary to the Slovene Intellectual Property Law or ZASP, adopted in 1995. The purpose of this Act is to protect the copyrights of authors and their work from the field of literature, science and art, as well as the copyrights of performers, publishers, etc. [3]. To that end the overall approach to plagiarism should be reviewed and not regarded an offence solely when it forms a part of student's grade.

Having spotted the problem, a small project was proposed in the course English in Logistics, explaining to a single group of students what plagiarism was, that it was considered as intellectual theft, and was contrary to the Statute of the University as well as the academic norms, values and requirements, regardless of whether it was done accidentally or not. It was made clear that such actions not only discouraged other students but also distorted the efforts of the teachers. As future intellectuals, it is the students who enhance or damage the reputation of the institution, at which they study and will acquire their academic title. Furthermore, the same group of students, although only briefly, was familiarized with different citation methods and their usage as well as with different methods of searching and using reliable internet sources, dictionaries and translation tools.

\section{A. Plagiarism detection}

The problem described above is not isolated to this particular case. In fact, with the spread and wide use of the internet, internet plagiarism is becoming a ubiquitous issue at several educational institutions, especially as today English has become a global lingua franca. That is why it is not surprising that a course English as a foreign language, too, has become much more susceptible to plagiarism than other courses or modules taught in Slovene. On the other hand, it is also much easier to identify plagiarism in non-native speakers if one pays attention to the most obvious signs that have already been described in detail by Bates and Fain [4]. The most common ones in students' assignments we identified were the following:

- Language, writing style, vocabulary, tone, and grammar were above the students' actual level;

- Pronouns did not correspond to the gender of the text producer;

- Web sites listed in citations were inactive;

- Look of grey letters in the text;

- Strange and poor layout such as more than one font type in a single text, references to hyperlinks, paragraphs with background color, strange texts or lines at the top or bottom of the page were indications that the text was downloaded or copypasted from the web;

- References to accompanying material that was not included in the text;

- Quotes in the paper did not have citations;

- The length of the paper was considerably longer than instructed;

- Certain information in the copy-pasted text was changed to the extent that the text did not make sense anymore.

To confirm the suspicion that students have plagiarized from the internet, the assignments simply need to be checked. Usually, a simple search using the web search tool Google by typing a phrase in the search box using quotation marks should do. However, some students often use different strategies and copy-paste chunks of paragraphs from various websites and glue them into one text. For this reason different plagiarism detection software tools can be used to confirm the suspicion. Ideally each institution would also provide access to such software at the institutional level to students, so they could learn what is acceptable paraphrasing.

\section{B. Possible reasons for plagiarizing}

Within the 8-week course students held presentations on specific topics which formed part of their oral examination. Prior to that, they had to submit a 500-600 word report, which is where plagiarism was first identified. But why? Finding the right reasons as to why students plagiarized and submitted work as their own without citing may help teachers and lecturers to lessen the opportunities for further plagiarism or may even help 
them prevent it altogether. In our case, some of the reasons might be:

- Due to the fact that English in Logistics is a core module at the Faculty, yet not of primary importance, the majority of students may believe the course, its assignments and thus the consequences of cheating to be less important or unimportant.

- With many course assignments being of extremely generic nature, students may think that it is their right to copy them off the internet.

- One of the main reasons is also believed to be the fear of holding presentations in a foreign language, which for some students, whose command of the English language was not fluent, was face threatening and stressful. For this reason students were not willing to paraphrase or rewrite texts written by experts or native speakers.

- Until this date no formal action has been taken for plagiarizing assignments and no penalties have been enforced, which also drastically increases students' opportunities for trying.

- The fact that in the middle of the academic year modules have been consolidated from 15 to 8-week intense courses might have affected students' poor time management skills.

\section{METHODS}

In order to get a better understanding as to why students plagiarize we wanted to assess different aspects of students' online learning experience from their general experience and motivation to their overall satisfaction with e-learning. To this end, two semesters after elearning had been integrated into the traditional teaching mode, a special random survey has been carried out in different foreign language groups in order to solicit students' views on e-learning. We were furthermore interested in the students' satisfaction with the level of difficulty of e-materials and quizzes they had to do on a weekly basis. We also wanted to know whether e-learning helped them with foreign language terminology acquisition and if they believe that the upcoming interactive quizzes would make learning foreign language terminology easier and more fun. At the same time students were asked to self-asses their internet and computer skills. The size of the target group featured 36 first and second year students from 4 different groups. The module consisted of 8 lectures, i.e. class sessions and 23hour e-learning lessons. The latter comprised Module support and e-materials on topics studied in class. The questionnaires were analyzed using the statistical analysis software SPSS 16.0 for Windows.

The second cohort featured 120 first-year students (ages 18-20) from 5 groups of the same module. 2 groups were from the dislocated unit of Krsko, the others were from Celje, where the Faculty is also situated. Our aim was to analyze students' uploaded assignments using plagiarism detection software, where each week a different group leader was to produce a 500-600 word report on the topic which the students then presented in groups of 3-5 in class. The oral presentation accounted for 30 per cent of their overall mark.

\section{DISCUSSION}

When evaluating students' satisfaction of the integration of e-learning into the traditional teaching mode based on the questionnaires, it was surprising to discover that 36.1 $\%$ still preferred traditional teaching mode, $38.9 \%$ neither agreed nor disagreed with it, and only $25 \%$ favoured the new teaching mode. This outcome may be one of the reasons why students engage in plagiarism. To this end, more time should be invested in showing the students the advantages of e-learning and offering them constant support while using it.

The relevance and quality of e-materials, on the other hand was assessed using grades 1-5 $(1=$ not good, $5=$ very good) whereby $50 \%$ of all students marked ematerials with 3 and the overall mark was 3,083. The reason for that may be cultural, as in Slovenia students still tend to prefer teacher-centered passive learning, whereas the materials are designed so as to encourage and facilitate active learning. However, this trend is now in the process of changing. As for the level of difficulty, one third of interviewed students rated the level of difficulty of the quizzes with 8 . Furthermore, to the question whether e-learning helped students with logistics terminology acquisition or not, $69.4 \%$ opposed and only $30.6 \%$ agreed. On the contrary, the vast majority $(88.9 \%)$ agreed with the fact that interactive quizzes would make learning terminology easier and more fun while only a minority $(11.1 \%)$ disagreed.

Finally, students were also asked to self-assess their internet and computer skills using grades 1-3 (1 as not good, 2 as average, 3 as very good). $77.8 \%$ rated their knowledge of computers and internet as good and only 1 student $(2.8 \%)$ as not good. $19.4 \%$ rated their knowledge as very good. This result is in line with the EU survey entitled Young Europeans through statistics [5], where young persons' computer skills and internet use were surveyed. Slovenia recorded the largest shares of young people (aged 16-24 years) with high computer skills (65 $\%$, followed by Luxemburg (61\%), Denmark and Austria $(58 \%)$. The skills included the following abilities: copy or move a file or folder, use copy and paste tools to duplicate or move information within a document, use basic arithmetic formula (add, subtract, multiply, divide) in a spreadsheet, compress files, connect and install new devices, such as a printer or a modem and write a computer program using a specialized programming language. Those who ticked 5 or all items were classified high level [5]. Having worked with the students in class and based on their submitted assignments I got the impression that the self-assessment of their computer knowledge was not entirely objective.

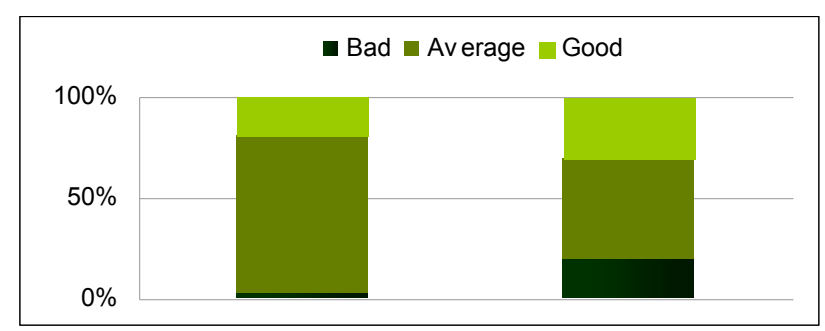

Figure 1. Self-assessment of computer skills and Assessment of elearning and e-materials 
In the second part of the analysis, which featured 120 first-year students we wanted to find out whether a simple warning against plagiarism would suffice. To this end we warned a group of 26 students against plagiarizing, whereas students from other groups have not been explicitly warned. Then, their submitted reports (63) were scanned using plagiarism detection software called Viper. Electronic plagiarism detection software Viper is available online and can be downloaded free of charge on several websites (http://www.powerfulwords.co.uk/scan.php). The program scans the text and not only compares it against more than 6 billion web pages but also against all work that was previously submitted to the company. The program then identifies the content in the scanned text and matches it to the relevant sources. Depending on whether the content that was matched with the found websites had been cited or not, one can confirm whether the student has plagiarized or not. Anything below $12 \%$ is regarded as low risk plagiarized material, $13-20 \%$ as medium risk of containing plagiarized material, while with anything over $21 \%$ the risk of containing plagiarized material is high and it is advised to examine it in greater detail. [6]. It was interesting to note that those students who had not been warned in advance submitted texts with the average word count of 856 , while the others had approximately 669 words. Only 11 students $(17 \%)$ did not plagiarize at all. These students were from the group that had been warned against plagiarizing as well as from the group that had not been warned. However, their topics were all based on domestic rather than international issues. Further interesting is the fact that the average word count in their reports was 441, which is almost half of what other students produced. This comparison confirmed our assumption above, that considerably longer texts than instructed are a sign for potential plagiarism.

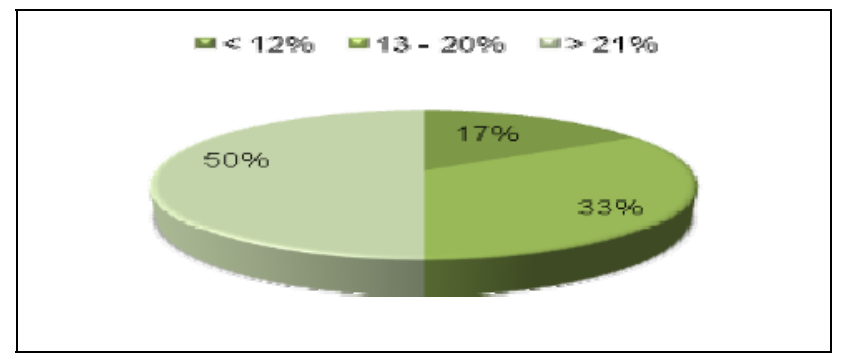

Figure 2. Plagiarism rate

In order to check the correlation between the "Total Word Count" and "Plagiarism Rate" variables the Spearman's Correlation non-parametric test was used, which showed a weak positive relationship between them (see Table 1).

TABLE I.

CORRELATION BETWEen TOtAL Word COUNT AND Plagiarism RATE

\begin{tabular}{|c|c|c|}
\hline \multicolumn{3}{|c|}{ SPEARMAN'S RHO } \\
\hline & Total Word Count & Plagiarism Rate \\
\hline Correlation Coefficient & 1.00 & 0.363 \\
\hline Sig (2. tailed) & 0.003 & \\
\hline $\mathrm{N}$ & 63 & 63 \\
\hline Correlation Coefficient & 0.363 & 1.00 \\
\hline Sig (2. tailed) & & .003 \\
\hline $\mathrm{N}$ & 63 & 63 \\
\hline
\end{tabular}

Kolmogorov-Smirnov normality test indicated that distribution of variables "Total Word Count" $(\mathrm{P}=0.00$, Skewness $=1.238$, Kurtosis $=2.129$ ) and "Plagiarism Rate" $(\mathrm{P}=0.04$, Skewness $=-0.241$, Kurtosis $=-1.178)$, differed significantly from normality. Therefore both variables were analyzed using Mann-Whitney test for the differences against plagiarism warning.

TABLE II

MANN-WHITNEY TEST STATISTICS

\begin{tabular}{|l|l|c|l|}
\hline \multicolumn{1}{|c|}{ Variable } & Mann-Whitney $\mathbf{U}$ & $\mathbf{Z}$ & Sig. (2-tailed) \\
\hline Plagiarism Rate & 471.50 & -0.133 & 0.893 \\
\hline Total Word Count & 333.50 & -1.851 & 0.064 \\
\hline
\end{tabular}

Mann-Whitney test did not show lower plagiarism rate between those students who have been warned. (Sig. = 0.893 ). The absolute value $Z$ was extremely low. Also, the number of words in reports decreased, however such differences are not significant for this tests (Sig. $>0.05$, $\mathrm{Z}<|1.9|)$.

Based on a more detailed analysis of the plagiarized assignments we found out that those students who had been warned in advance continued to plagiarize from the internet, using paragraphs from different websites which they then glued together, most probably to make it seem less obvious. This also influenced the length of their papers.

\section{PREVENTING INTERNET-PLAGIARISM}

The internet has seen a rapid development and expansion in the past few years and has become a hub for copyright infringements. According to a survey by the Association of Teachers and Lecturers, which polled 300 teachers form colleges and further education colleges across United Kingdom, 58 per cent of teachers described web plagiarism as a problem [7]. Moreover, "some 28 per cent of these teachers estimated that at least half of the work returned by pupils included content simply copied and pasted from the internet" [ibid].

However, a more detailed knowledge of the internet search engines' performance also makes it easy to detect such acts.

But how can we deter or prevent academic malpractice? We believe that the issue should be tackled from different angles. First and foremost, the University should adopt a more holistic approach, take harder measures when dealing with academic malpractice and educate students about academic integrity, requirements and conventions at the very beginning of their studies. For if students continue copying other peoples' ideas throughout their study course they will fail to develop the skill to think critically and creatively and thus become unmotivated and passive learners. Moreover, they will most probably continue to do so throughout their lives, as they will doubt themselves and their own abilities.

To this end, a clear-cut definition of academic malpractice is necessary so that students are aware of what is or is not acceptable. Different studies have shown that detecting plagiarism and punishing students is much more time consuming and ineffective than encouraging them to adopt academic values and requirements [7] and [8]. That is why all students should complete a core course in research ethics in their first year of study. Also, investing 
in renowned plagiarism detection software and offering it to both students and staff could help deter plagiarism. Students have also pointed out that versatile pedagogical process would attract their attention more and make learning easier. Therefore, there is a possibility that students will engage more in their studies and the overall plagiarism rate will drop once e-materials are made interactive. This may indicate a move from passive to active, from teacher-centred to student-oriented learning. Furthermore, it is important that lecturers and assistants do not turn a blind eye to this issue, for students will continue to copy ideas and materials from others. Last but not least, students' overall workload should be taken into account when assigning projects, especially when e-learning is still in the first phase of integration into the traditional teaching process, when it is still too soon to weigh all the advantages and drawbacks against one another.

\section{CONCLUSION}

The use of e-learning in form of online quizzes, podcasts, IT-tools and software, and especially the internet contributes to lectures as such and has become inevitable and a core instrument for contemporary foreign language learning. However, the degree to which the students are satisfied with the new teaching mode also plays an important role. In the digital age, internet-plagiarism remains a problem, all teachers will have to confront. According to the aforementioned study from the UK education institutions, 55 per cent of teachers surveyed admitted that their school has no policy to deal with plagiarism [7]. In Slovenia, and particularly at this Faculty, modern technology is rapidly being integrated into traditional teaching modes and is already starting to recognize and eliminate the negative impacts or sideeffects of this trend. Furthermore, many further education institutions in Slovenia have recently started investing in plagiarism detection tools.

The main aim of this paper was to present the problem of web-plagiarism most teachers are dealing with today in higher education where students' work is mostly based on independent research and study. We also highlighted the reasons for this and outlined some points as to how this problem could be tackled. To this end, we first and foremost wanted to get the impression of what the situation is like at the moment. Then, we tried to motivate students instead of punishing them for their actions.
However, due to the scope of this issue this is just the first step towards can and should be done.

Therefore, conducting a similar survey or research in a not too distant future would be most interesting, after all students have completed a course in research ethics and citation methods. Moreover, further research on this topic that was to include not only foreign language courses but also other modules, taught in Slovene as well as a research with other universities in Slovenia would also provide a greater insight into this issue.

\section{REFERENCES}

[1] D. Türk, "Predsednik republike o stanju visokega solstva v Sloveniji”, Sporocilo za javnost: govor, 2008, available from: http://www.up-rs.si/up-rs/uprs.nsf/dokumentiweb/1FD04C56487 8BD35C1257403005066F6?OpenDocument. Accessed on: 17 April 2008.

[2] Univerza v Mariboru, "Statut Univerze v Mariboru: precisceno besedilo", Maribor: Univerza, 2001, p. 63-65.

[3] Uradni list Republike Slovenije, "Zakon o avtorskih in sorodnih pravicah - ZASP”, OJ RS, No. 21/95 from 14. 4. 1995, available at http://www.listanjezakonov.com/ZASP UPB3/F000001.HTM Accessed on: 17 April 2008.

[4] P. Bates and M. Fain, "Cheating 101: Detecting Plagiarized Papers", Kimbel Library Presentations, 2004, available from: http://www.coastal.edu/library/presentations/plagiarz.html Accessed on: 15 October 2008.

[5] T. Allen and L. Corselli-Nordblad, "Youth Summit in Rome: Young Europeans through statistics", in Eurostat Press Office. [44] 2007. 24-25 March 2007, available from: http://ec.europa.eu/eurostat. Accessed on: 15 October 2008.

[6] English Essays, "Free Plagiarism Scanning and Detection Software, 2004, available from: http://www.englishessays.org.uk/ free-plagiarism-scanner-scan.php. Accessed on: 30 September 2008.

[7] iTnews (2008) Teachers despair at web plagiarism. 22 January 2008 iTNews online. Available from: http://www.itnews.com.au/ News/68663,teachers-despair-at-web-plagiarism.aspx Accessed on: 17 October 2008.

[8] J. Caroll (2004) Institutional Issues in deterring, detecting and dealing with student plagiarism. Available from: www.jisc.ac.uk/ media/documents/publications/plagiarismfullreport.doc. Accessed on: 16 October 2008.

\section{AUTHORS}

S. Orthaber is with the Faculty of Logistics, University of Maribor, Celje, SI-3000, Slovenia (e-mail: sara.orthaber@uni-mb.si).

This article was modified from a presentation at the The International Conference on E-Learning in the Workplace (ICELW), June 2008, New York, USA. Manuscript received 15 July 2008. Published as submitted by the author. 